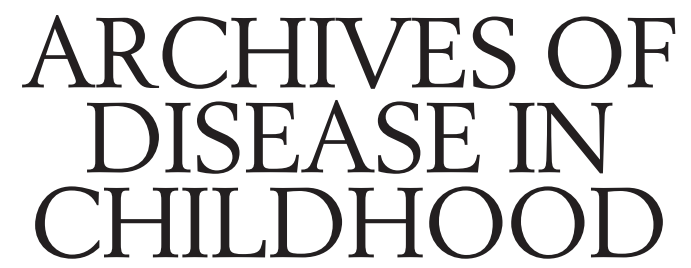

The Fournal of the Royal College of Paediatrics and Child Health

\title{
Annotations
}

\section{Health education: evidence of effectiveness}

\section{Health education: nature and purpose}

Even a limited discussion of the nature of health promotion is beyond the scope of this article.

We should, however, note that there is a divergence of opinion about its major goals and that it is not synonymous with health education. Its philosophy has been discussed in detail elsewhere. ${ }^{1-6}$

Health promotion may be viewed as a global strategy which incorporates health education.

Health education is defined operationally as:

'.... any intentional activity which is designed to achieve health or illness related learning, ie, some relatively permanent change in an individual's capability or disposition. Effective health education may, thus, produce changes in knowledge and understanding or ways of thinking; it may influence or clarify values; it may bring about some shift in belief or attitude; it may facilitate the acquisition of skills; it may even effect changes in behaviour or lifestyle' (p11). ${ }^{2}$

\section{Effectiveness}

We are, at present, witnessing a demand for evidence-based medicine within a general climate of cost cutting and a concern to demonstrate 'health gain' and it is not surprising that health education should be subject to the same demands. The principles and practice of evaluating health education cannot be addressed here. ${ }^{278}$ It is, however, worth noting the fact that health education interventions are frequently under resourced and often fail to meet acceptable theoretical and professional standards; careful scrutiny of programme design is, therefore, essential before drawing conclusions about effectiveness and efficiency. ${ }^{9}$ The success of the programmes discussed below are, in no small way, due to their meeting minimum design standards.

Health education success: a selective review Seven specific areas have been selected for review:

- Childhood asthma

- Oral health

- Accident prevention

- Breast feeding

- Nutrition education and children

- Sexual health
- Social and mental health in respect of bullying, child abuse, and preschool education.

These particular topics were selected because of their inclusion in three recent reviews of effectiveness: (i) a wide ranging 16 volume review Improvement of the Effectiveness of Health Education and Health Promotion published by the International Union for Health Promotion and Education (IUHPE), ${ }^{10}$ (ii) specific UK briefing reviews of breast feeding and child home accidents, ${ }^{112}$ and (iii) a major, comprehensive review of nutrition education. ${ }^{13}$ Exemplars have been included only if the reviewers judged the intervention to be effective and if the research designs were either true experimental or quasiexperimental.

CHILDHOOD ASTHMA

Colland described an asthma intervention which met most programme design requirements ${ }^{14}:$ it was theory based and used relevant educational methods (namely 10 hourly sessions incorporating workshops, group discussion, role play, games, and skills training); it was also supported by an appropriate workbook learning resource. Eighty two children aged 8-13 received the educational programme and, by comparison with 30 controls, the experimental group demonstrated: greater knowledge of asthma and its management; better coping skills; fewer restrictions in daily activities; greater self confidence and a more positive attitude to their condition; reduction in anxiety; more effective problem solving; enhanced self efficacy beliefs; satisfaction with the programme and greater compliance; evidence of reduced morbidity.

\section{ORAL HEALTH}

The IUHPE review listed five examples of successful interventions in relation to oral health. ${ }^{15}$ The oral health studies demonstrated improvement in a number of general dental preventive measures ${ }^{16}$ and dietary change ${ }^{17}$ in secondary schoolchildren. One study revealed success in influencing pharmacists' intentions to prescribe sugar free paediatric preparations $^{18}$ and two other studies described effective interventions to promote water fluoridation. ${ }^{19} 20$

ACCIDENT PREVENTION

The IUHPE review ${ }^{21}$ also included evidence of success in increasing use of car seats for babies, ${ }^{22}$ reductions in home 
accidents, ${ }^{23}{ }^{24}$ and scalding. ${ }^{25}$ A general review by Harker ${ }^{12}$ also described successful attempts to reduce tap water scalds ${ }^{26}$ and to improve skills and reported practices in road safety behaviours in schoolchildren. ${ }^{27}$

\section{BREAST FEEDING}

The decision to breast feed seems to depend substantially on beliefs about the relative costs and benefits of breast and bottle feeding. The benefits derive typically from the value attached to the health of the baby and the enhancement of bonding. On the other hand, the major cost is usually anticipated embarrassment. Normative pressures also play a part in determining behavioural intention while the provision of support after the decision has been made is of particular importance in determining whether or not breast feeding is maintained. In this latter context, success would seem to depend on the extent to which mothers are taught specific skills - such as the correct positioning of the baby - together with the provision of anticipatory guidance and arranging for a supportive environment both in and out of hospital - including both specific nursing support and more general social support. When favourable conditions are provided, there is evidence that health education can in fact result in success. For instance Jones et al demonstrated a difference of some $12 \%$ in breast feeding between intervention and controls when a lactation nurse provided appropriate support and education. ${ }^{28}$ The largest effect was in social groups IV and V.

Frank et al showed how counselling plus a support pack achieved a $43 \%$ rate of breast feeding at 23 months (compared with $30 \%$ controls) in a group of 343 low income mothers in a hospital context. ${ }^{29}$ In the intervention of Johnson et al, $67 \%$ of a group of women who received a referral card, 'manual' and bedside counselling, were breast feeding at the end of the fourth week compared with $16 \%$ of a minimal intervention group. ${ }^{30}$ Kistin et al used peer counselling with 59 mothers in a hospital setting and demonstrated a $93 \%$ incidence and $44 \%$ maintenance of breast feeding compared with $70 \%$ and $12 \%$ of controls. ${ }^{31}$

\section{NUTRITION EDUCATION AND CHILDREN}

Influencing dietary practices is not easy but it can be achieved in the right circumstances. Contento ${ }^{13}$ described two convincing interventions at the preschool and school level which demonstrated an improvement in the quality of food served by parents to their children ${ }^{32}$ and significant changes in knowledge, food preferences, and five out of 12 targeted behaviours in a school setting. ${ }^{33}$

\section{SEXUAL HEALTH}

The emergence of AIDS has added extra impetus to the need to provide effective sex education for young people. A number of studies-mainly from North America-have demonstrated that it is possible to achieve success in reducing the risk of HIV infection.

Two studies from the IUHPE review ${ }^{34}$ showed convincing changes in knowledge, beliefs, attitudes, self efficacy, and self reported changes in risky sexual practices in black and Hispanic students. ${ }^{35} 36$

\section{SOCIAL AND MENTAL HEALTH}

The final three examples of effectiveness presented here relate to bullying, child abuse, and the effect of providing appropriate preschool education. They are especially significant in that they indicate the potential benefits of programmes that address socioeconomic factors. ${ }^{37}$

Olweus described the results of a major intervention designed to address the problem of bullying in a school district in Norway. ${ }^{38}$ The target groups were schoolchil- dren, parents, and teachers. A wide range of educational methods was employed: group discussion, workshops, role plays, games, one-to-one counselling, booklets, and videos. Staff were trained and supportive policies were developed at both school and national level. There was a $50 \%$ reduction in bullying both in and out of school; incidence of victimisation fell from $2.6 \%$ to $0.6 \%$ in boys and $1.7 \%$ to $0.59 \%$ in girls. There was a reduction in truanting and antisocial behaviour.

The study of Barker et al of the effect of a child development programme on the incidence of child abuse is of particular interest. ${ }^{39}$ Some 30000 parents and children (largely from low socioeconomic groups) were involved in 24 UK health authorities. The programme centred on home visiting by 'first parent visitors' who made monthly visits lasting one hour over a period of a maximum of three years. Intervention methods were primarily counselling supported by cartoon books. A wide range of support skills were provided - including nutrition, health, language, and stress management-all within the context of an empowering relationship. There was a significant reduction in morbidity: 5.25 per 1000 of the experimental group (on child problem register) compared with 8.93 of the experimental group (general population); there was a $41 \%$ reduction in the incidence of physical abuse.

The Perry Preschool Program is the final study described here. ${ }^{40}$ Fifty eight black children received five weekly sessions lasting 30 minutes; parents received one 90 minute home visit. The programme focus was on 'lifeskills' designed to enhance children's cognitive and social development. Special emphasis was placed on school adjustment and the acquisition of social and behaviour skills. By the time the children had reached the age of $19,59 \%$ of those in the intervention group were employed (compared with $32 \%$ of controls); $38 \%$ had a college education ( $21 \%$ controls); $16 \%$ had special education ( $28 \%$ controls); there were 64 pregnancies (117 controls); they experienced a $31 \%$ arrest/detention rate ( $51 \%$ controls). The cost-benefit ratio was calculated as $9: 1$.

\section{Requirements for effective programmes}

Design sophistication is a characteristic features of the successful programmes described above. The requirements for efficient programmes might be summarised as follows:

- They should be based on relevant theory and, where possible, prior research

- They should be based on a sophisticated diagnosis of the social, psychological, and environmental determinants of the health or illness related behaviour

- Focus should not only be on knowledge but also on beliefs and relate to the individual's developmental stage

- Full account should be taken of the various 'pushes and pulls' of competing motivations on intention to act

- The importance of social pressures should be acknowledged

- Barriers to adoption and maintenance should be identified - especially environmental barriers

- Empowerment factors should be emphasised

- Education must be complemented by achieving a 'supportive environment'

- Interventions should be maximised by creating 'coalitions' between different settings and stakeholders. Maximum client participation should be a major goal. Coalitions should be supported by appropriate use of mass media.

- A sophisticated behavioural diagnosis should be matched by the use of appropriate education methods and learning resources 
- Health staff must be trained to use the appropriate educational methods.

School of Health and Community Care,

KEITH TONES

Leeds Metropolitan University,

Calverley Street,

Leeds LS1 3EH

1 Tones BK. Health promotion-a new panacea? fournal of the Institute of Tones BK. Health promotion-a

2 Tones K, Tilford S. Health education: effectiveness, efficiency and equity. London: Chapman Hall, 1994

3 World Health Organisation. Health promotion: a discussion document on the concepts and principles. Copenhagen: WHO, 1984.

4 World Health Organisation. Ottawa charter for health promotion. An international conference on health promotion, November 17-21. Copenhagen: WHO, 1986

5 Tones K. Health education, behaviour change and the public health. In Dettels R, McEwen J, eds. Oxford textbook of public health. Oxford: Oxford University Press, 1997.

6 Tones K. Radicalism and the ideology of health education. Health Education Research 1993;8:147-50.

7 Green LW, Lewis FM. Measurement and evaluation in health education and health promotion. Palo Alto, CA: Mayfield, 1986.

8 Sarvela PD, McDermott RJ. Health education evaluation and measurement: a practitioner's perspective. Madison, WI: Brown and Benchmark, 1993 .

9 Brook R, Lohr K. Efficiency, effectiveness, variations and quality. Medical Care 1985;23:710-22.

10 International Union for Health Promotion and Education. Improvement of the effectiveness of health education an health promotion. Utrecht: Dutch Cenre for Health Promotion, 1994.

11 Harker P. Promotion of breastfeeding maintenance. Briefing review No 2. Bristol: Department of Social Medicine, 1996.

12 Harker P. Health visitor prevention of child home accidents. Briefing review No1. Bristol: Department of Social Medicine, 1996.

13 Contento I. Nutrition education and implications. Fournal of Nutrition Education 1995;27:special issue.

14 Colland VT. Learning to cope with asthma: a behavioural self-management programme for children. Patient Education and Counselling 1993;22:141-52.

5 Schou L, Locker D. Oral health: a review of the effectiveness health education and health promotion. Utrecht: Dutch Centre Health Promotion, 1994.

16 Sogaard AJ, Holst D. The effect of different school based dental health education programmes in Norway. Community Dent Health 1988;5:169-84.

17 Holund U. Promoting change of adolescents sugar consumption: the 'Learning by Teaching' study. Health Education Research 1990;5:451-8.

18 Mackie IC, Worthington HV, Hobson P. A spoonful of sugar-free helps caries levels go down. Fournal of the Institute of Health Education 1992;30: 60-5.

19 Kuthy RA, Durkee J. Education: a key to fluoridation compliance. F Public Health Dent 1985;45:247-51.

20 Smith KG, Christen KA. A fluoridation campaign: the Phoenix experience. $\mathcal{f}$ Public Health Dent 1990;50:126-35.
21 Towner E. Unintentional injuries in childhood: a review of the effectiveness of health education and health promotion. Utrecht: Dutch Centre for Health Promotion, 1994.

22 Reisinger KS, Williams AF, Wells JK, John CE, Roberts TR, Podgainy HJ. Effect of paediatrician's counselling on infant restraint use. Pediatrics 1981; 67:201-6.

23 Schelp L. Community intervention and changes in accident pattern in a rural Swedish municipality. Health Promotion 1987;2:109-25.

24 Colver A, Hutchinson PJ, Hudson EC. Promoting children's home safety. BMF 1982;285:1177-80.

25 Katcher ML, Landry GL, Shapiro MM. Liquid-crystal thermometer use in pediatric office counselling about tap water burn prevention. Pediatrics 1989;83:766-71.

26 Thomas K, Hassanein RS, Christopherson ER. Evaluation of group well-child care for improving burn prevention practices in the home. Pediatrics 1984;74:579-82.

27 Thomson JA, Ampofo-Boateng K, Pitcairn T, Grieve R, Lee DN, Demetre JD. Behavioural groups training of children to find safe routes to cross the road. Br F Educ Psychol 1992;62:173-83.

28 Jones DA, West R, Newcombe RG. Maternal characteristics associated with the duration of breast-feeding. Midwifery 1986;2:141-6.

29 Frank DA, Wirtz S, Sorenson JW, Heeran T. Commercial discharge packs and breast-feeding counselling: effects on infant-feeding practices in a randomised trial. Pediatrics 1987;80:845-54.

30 Johnson CA, Garza C, Nichols B. A teaching intervention to improve Johnson CA, Garza C, Nichols B. A teaching intervention to impration
breastfeeding success. Fournal of Nutrition Education 1984;16:19-22.

31 Kistin N, Abramson MS, Dublin P. Effect of peer counselors on breastfeeding initiation, exclusivity, and duration among low-income urban women. Fournal of Human Lactation 1994;10:11-6.

32 Koblinsky SA, Guthrie JF, Lynch L. Evaluation of a nutrition education program for Head Start parents. Fournal of Nutrition Education 1992;24:413.

33 Perry CL, Mullis RM, Maile ML. Modifying the eating behavior of young children. Fournal of School Health 1985;55:399-402.

34 Aggleton P. Sexual behaviour and HIV/AIDS: a review of the effectiveness of health education and health promotion. Utrecht: Dutch Centre for Health Promotion, 1994.

35 Jemmott J, Jemmott LS, Fong GT. Reductions in HIV risk-associated sexual behaviours among black male adolescents: effects on AIDS prevention intervention Am f Public Health 1992;82:372-7.

36 Walter H, Vaughan R. AIDS risk reduction among a multiethnic sample of urban high school students. $\mathscr{F} A M A$ 1993;270:725-30.

37 Hosman C, Veltman N. Prevention in mental health: a review of the effectiveness of health education and health promotion. Utrecht: Dutch Centre for Health Promotion.

38 Olweus D. Bullying among schoolchildren: intervention and prevention. In: Peters V, McMahon RJ, Quinsey VL, eds. Aggression and violence throughout the life span. Newbury Park: Sage, 1992.

39 Barker W, Anderson R, Chalmers C. Child protection: the impact of the child development programme. Bristol: University of Bristol Early Childhood development programme. Bri

40 Berruetea-Clement JR, Schweinhaert LJ, Barnett WS, Epstein AS, Weikart DP. Changed lives: the effects of the Perry Preschool Program on youths through age 19. Michigan: High Scope Press, 1984.

\section{Vitamin A prophylaxis}

It has been little more than a decade since the initial observation of the dose dependent relation between the severity of vitamin A deficiency and childhood mortality, ${ }^{1}$ quickly followed by the publication of a controlled trial in which children of preschool age, randomised to receive large doses of vitamin A every six months, died at only two thirds (or less) the rate of control subjects. ${ }^{2}{ }^{3}$ In the short interval since this trial, an initially sceptical scientific community has declared control of vitamin A deficiency a major international goal ${ }^{4-6}$ and potentially one of the most cost effective of all health interventions. ${ }^{7}$

The story did not begin in the 1980s. A host of animal studies and anecdotal clinical reports during the first third of the century, soon after vitamin A was discovered, suggested a close, potentially causal relation between vitamin A status and morbidity and mortality from infection. These are detailed elsewhere. ${ }^{8}$

\section{Vitamin A prophylaxis and mortality}

For ethical and logistic reasons the observational study ${ }^{1}$ has never been repeated, though a large number of intervention trials have been carried out. Eight were initially considered to be suitably rigorous for inclusion in an independently commissioned meta-analysis (table 1 ). ${ }^{9}$ The results were remarkably similar, particularly given the wide differences in culture, dietary habits, disease patterns, and malnutrition of the populations studied, the differences in study design, and the variation in the potential effectiveness of the strategies used to improve vitamin A status. ${ }^{210-16}$

On an intent to treat basis, six of the eight studies recorded a statistically significant reduction in mortality among children assigned to receive vitamin A supplements (19 to $54 \%$ ), even though not all those assigned vitamin A complied with the treatment. ${ }^{28}$

\section{Negative results}

Two 'outlier studies', in which no reduction in mortality was observed, deserve mention. The Hyderabad trial ${ }^{13}$ had a series of problems that only became apparent after publication from an exchange of letters to the editor: children were routinely examined and treated for disease each week by specially trained health workers. This may explain why both the treatment and control arms experienced mortality much lower than anticipated. This general reduction in mortality drastically reduced the power of the study to detect an effect attributable to the vitamin A supplement (mean reduction 6\%, 95\% confidence interval 